\title{
Burns by Ionizing and Non-Ionizing Radiation
}

Giovanni Alcocer* \& Priscilla Alcocer

Independent Researches, Guayaquil-Ecuador. Email: giov_alc_science@hotmail.com*

Giovanni Alcocer: Master in Physics with Specialization in Astrophysics and Medical Physics, Professor of Physics, Advanced Mathematics and Science in General, Author of the Recognized and Renowned Articles: The Fundaments of the Mass: Gravitation, Electromagnetism and Atom

DOI: http://doi.org/10.46382/MJBAS.2021.5107

Copyright: (02021 Giovanni Alcocer \& Priscilla Alcocer. This is an open access article distributed under the terms of the Creative Commons Attribution License, which permits unrestricted use, distribution, and reproduction in any medium, provided the original author and source are credited.

\section{ABSTRACT}

This article consists of the study and investigative analysis of the effects of burns by radiation in humans. Cases of nuclear accidents, such as Chernobyl (ionizing radiation) and the effects of non-ionizing radiation such as infrared and microwave radiation are detailed. It is examined cases of injuries and burns by ionizing radiation due to irradiation (diagnostic equipment and medical treatment: $X$-rays, radiotherapy) or contamination (nuclear accidents, wars). Injuries and burns are also caused by nonionizing radiation, such as visible light (laser), ultraviolet, radiofrequency.

There are numerous biological issues in the case of tissues, the ionizing radiation (ionizing particles and electromagnetic radiation: X-rays, gamma rays and high energy ultraviolet) can cause damage mainly in the DNA. This can cause mutations in its genetic code and cancer 3 . In addition, damage to other tissues and organs can occur, as well as burns, erythema and lesions. The biological effects of nonionizing radiation are currently under investigation. Burns, erythema and lesions can also occur due to the following types of radiation: low energy ultraviolet, visible light, infrared, microwave, radiofrequency, electromagnetic fields. The purpose of this article is to provide an exhaustive analysis of all types of both ionizing and non-ionizing radiation and their effects on living beings. Finally, it is important to follow all safety and radiation protections against both ionizing and non-ionizing radiation.

Keywords: Radiation, Ionizing, Non-ionizing, Radiation effects, Burns.

\section{Introduction}

X-ray was discovered by Roentgen in 1895. The first radiation burns were recorded in 1901 by Becquerel, who inadvertently dropped a radio container producing a radio burn in his forearm, causing erythema and ulceration which took a few weeks to heal ${ }^{2}$. Subsequently, it was deliberately done by Pierre Curie. During this time, the first injuries were mainly due to skin reactions and burns on the hands of those who worked with the radiology equipment, but other types of lesions were also detected, including cancers attributed to radiation ${ }^{3}$. The historical development of ionizing radiation is shown in the table 1 :

Table 1. First 100 years of ionizing radiation and radioactivity ${ }^{4}$

\begin{tabular}{|c|c|}
\hline 1895 & The x-rays are discovered by Röentgen and the first $x$-ray image is produced \\
\hline 1896 & The radioactivity in uranium is discovered by Becquerel \\
\hline 1898 & Marie and Pierre Curie identify radioactive elements: radio, thorium and polonium \\
\hline 1901 & $\begin{array}{l}\text { First medical uses of radioactive substances. Danlos and Block located radius in } \\
\text { tuberculous skin lesions }\end{array}$ \\
\hline 1918 & Rutherford observed constituents of the atomic nucleus \\
\hline 1923 & $\begin{array}{l}\text { George de Hevesey performed studies of first biological tracers with radioactive material } \\
\text { in plants and rats }\end{array}$ \\
\hline
\end{tabular}




\begin{tabular}{|c|l|}
\hline $\mathbf{1 9 2 8}$ & Formation of the International Commission of Radiological Protection (ICRP) \\
\hline $\mathbf{1 9 3 0}$ & $\begin{array}{l}\text { Lawrence and Livingstone built the first cyclotron for accelerated charged atomic } \\
\text { particles }\end{array}$ \\
\hline $\mathbf{1 9 3 4}$ & Fermi produced artificial radioactivity \\
\hline $\mathbf{1 9 4 2}$ & First controlled nuclear fission reaction, Chicago \\
\hline $\mathbf{1 9 4 5}$ & First atomic bomb detonated in the Los Alamos desert, New Mexico \\
\hline $\mathbf{1 9 4 5}$ & First atomic bomb launched in Hiroshima and Nagasaki \\
\hline $\mathbf{1 9 4 8}$ & $\begin{array}{l}\text { Emilio Segré discovers and gives its name to the first radioactive element Artificial } \\
\text { Tecnecio 99m, California, USA }\end{array}$ \\
\hline $\mathbf{1 9 5 4}$ & Thermonuclear bomb detonated, Bikini Island, Pacific Ocean \\
\hline $\mathbf{1 9 5 4}$ & Industrial scale development of a nuclear power reactor, Obninsk, Russia \\
\hline $\mathbf{1 9 5 7}$ & Accidental radiation release, Windscale, UK \\
\hline $\mathbf{1 9 6 4}$ & Anger invented the gamma camera for radionuclide imaging \\
\hline $\mathbf{1 9 7 2}$ & Godfrey Hounsfield patented computed tomography X-rays (CT), UK \\
\hline $\mathbf{1 9 7 9}$ & Three Mile Island reactor accident, USA \\
\hline
\end{tabular}

A table of the different types of radioactive isotopes and their respective use is showed in the table 2:

Table 2. Radioactive Isotopes and their respective uses

\begin{tabular}{|l|l|}
\hline Use & Radioactive Isotopes \\
\hline Telegammatherapy & Cobalt 60 \\
\hline Radiotherapy (high intensity) & Iridium 192 \\
\hline Radiotherapy (low intensity) & Cesium 137, Iridium 192 \\
\hline Irradiation of blood products & Cesium 137, Cobalt 60 \\
\hline Industrial irradiation & Cesium 137, Cobalt 60 \\
\hline Thickness measurements & $\begin{array}{l}\text { Cesium 137, Kriptun } 85, \text { Cobalt } 60, \text { Americium } \\
241\end{array}$ \\
\hline Level measurements & Cobalt 60 \\
\hline
\end{tabular}




\begin{tabular}{|l|l|}
\hline Humidity and density measurements & Cesium 137, Americium 241, Beryllium 10 \\
\hline Industrial radiographs & Iridium 192, Cobalt 60 \\
\hline X-ray fluorescence analysis & Plutonium 238, Iron 55, Americium 241 \\
\hline Gas phase chromatography & Nickel 63, Tritium (Hydrogen 3), \\
\hline Smoke detectors, radioactive lightning rod & Americium 241 \\
\hline
\end{tabular}

The ionizing radiation has effects on the skin which are well known. X-rays of 200-300 keV were used in radiotherapy before the use of super voltage radiotherapy. These X-rays' micropenetrating produced erythema, peeling and hair removal. It limited their use, since the dosimetry depended of the patient's tolerance.

As a result of this, different dosages: erythema dose, desquamation dose and hair removal dose were estalished ${ }^{8}$. Hair follicles are radiosensitive, and hair removal is another response to ionizing radiation. In ancient times, $\mathrm{X}$-rays of low energy (10 to $20 \mathrm{keV}$ ) were used to treat hair conditions such as ringworm ${ }^{8}$.

The radiation consists of the energy transfer from a source to the environment without the necessary presence of a medium $^{5}$. The interaction between radiations with matter produces some biological and non-biological effects such as lesions, erythema and burns. These effects are based in the kind of wave, the particle energy, the particle type (ionizing or nonionizing) and the material or medium which the radiation impacts ${ }^{5}$.

Electromagnetic radiation (Rem) are electromagnetic waves carrying energy without the necessity of a material or medium and with the same speed of light in a vacuum ${ }^{2,5}$. The unit of frequency is Hertz $(\mathrm{Hz})$, the unit of wavelength is $\mathrm{m}, \mathrm{cm}, \mu \mathrm{m}, \mathrm{nm}$, and the unit of energy is Joule, $\mathrm{J}, \mathrm{eV}, \mathrm{MeV}$. The group of all electromagnetic radiation is called the electromagnetic spectrum ${ }^{5}$. Below $100 \mathrm{kHz}$ are the electromagnetic waves which correspond to electric and magnetic fields, high voltage lines. Frequencies from $100 \mathrm{kHz}$ until $300 \mathrm{MHz}$ approximately are called radio frequencies and they are non-ionizing radiation. The microwaves are in the range from $300 \mathrm{MHz}$ to approximately $300 \mathrm{GHz}$ and they are also non-ionizing radiation. Above the microwave frequency is the infrared region (non-ionizing) and above this is the visible region (light) (non-ionizing) and finally the low and high energy ultraviolet radiation (ionizing radiation: high energy ultraviolet). Lastly, is ionization radiation: X-rays and gamma rays ${ }^{5}$.

Radiation (electromagnetic waves) is also made up of small energy packages called photons (massless particles which travel at the speed of light $)^{5}$. The concept of X-rays or gamma rays composed of photons is very important in radiobiology ${ }^{2}$. When photons are absorbed into a living material, the energy is deposited in discrete packets or photons in tissues and cells. The energy of the individual photon will determine if it is possible to get the rupture of a chemical bond and to start the events which culminate in biological damage ${ }^{2}$. In relation to the biological effects, the electromagnetic radiation is usually considered ionizing ${ }^{2}$, if they have a photon energy in excess of $124 \mathrm{eV}$ (wavelength shorter than $10^{-6} \mathrm{~cm}$ or $1 \mu \mathrm{m}$ ). Most biological systems experiments involve Gamma rays or X-rays. The X-rays are created outside the nucleus (a tube of X-ray, deceleration of electrons and when an electron jumps 
from one orbit to another inside the atom). Gamma rays are produced within the nucleus (radioactive isotopes, excess energy from unstable nuclei) ${ }^{2,3}$.

The ICRU (International Commission of Radiation Units and Measures) establishes the concepts of units and quantities of radioactivity and radiation. The ICRP (International Commission of Radiological Protection) establishes the concepts and regulations of units and quantities used in radioprotection, such as: absorbed dose, activity, effective dose, equivalent dose, linear energy transfer, radiological weighting factor, tissue weighting factor ${ }^{3}$.

\subsection{Ionizing Radiation}

The difference between the ionizing and non-ionizing radiation is in the amount of energy of the individual photon and not in the amount of the total energy ${ }^{2}$. The amount of ionization depends of the energy level ${ }^{3}$.

Ionizing radiation is caused by particles and electromagnetic waves of gamma rays and photons ${ }^{3}$. Ionization or excitation is produced with the absorption of radiation energy in biological materials. The excitation is produced when the electron (which received the radiation energy) is released from the atom orbit (high energy level) or molecule without the expulsion of the electron from the atom. The ionization is produced when the electron (which receives high energy) is expelled from the atom or molecule. It can change the biological and chemical conditions and cause damage to the molecule. The low energy ultraviolet radiation can lead to ionization in some circumstances $^{3}$. The lower energy limit for ionizing radiation is the ultraviolet region of high energy ${ }^{3}$.

The energy released by each ionization is around $34 \mathrm{eV}$ (air ionization). It is sufficient to get the rupture of a strong chemical bond. The associated energy of a carbon bond $(\mathrm{C} \stackrel{\mathrm{m}}{=} \mathrm{C})$ is approximately $4.9 \mathrm{eV}$. Typically, the energy required to break a molecular bond is from 2 to $5 \mathrm{eV}$.

A table of the radiation classification is showed in the table 3:

Table 3. Radiation classification ${ }^{5}$

\begin{tabular}{|c|c|c|c|}
\hline & & & Alpha \\
\hline & & & Beta \\
\hline & & Mass Particles & Neutrons \\
\hline & Ionizing & & Others: Protons, Heavy Nuclei \\
\hline Radiation & & $\begin{array}{c}\text { Electromagnetic } \\
\text { Radiation }\end{array}$ & $\begin{array}{l}\text { High energy X-ray and gamma rays, high } \\
\text { energy ultraviolet }\end{array}$ \\
\hline & & & Ultraviolet (low energy) \\
\hline
\end{tabular}




\begin{tabular}{|l|l|l|l|}
\hline & Non-Ionizing & $\begin{array}{c}\text { Electromagnetic } \\
\text { Radiation }\end{array}$ & Visible light \\
\hline & & & Infrared \\
\hline & & & Microwave \\
\hline & & & Radiofrequency \\
\hline & & & Electric and magnetic Fields \\
\hline
\end{tabular}

Humans are naturally exposed to ionizing radiation: $55 \%$ of radon, $8 \%$ of cosmic radiation, $8 \%$ of terrestrial radiation, $11 \%$ of internal radiation ${ }^{6}$. On other hand, the exposure of human beings artificially is: $11 \%$ of X-rays, $4 \%$ of nuclear medicine, $3 \%$ of consumer products. ${ }^{6}$. The cosmic radiation comes from space through cosmic rays to our planet ${ }^{3}$. Also, it is in the form of radon element emissions in the air $^{3}$.

The radioactive isotopes occurring naturally enter all living beings ${ }^{3}$. Radiation doses when administered in large quantities can cause damage ${ }^{3}$. Some sources of ionizing radiation are primordial radionuclides (Thorium, Rubidium, Potassium and Uranium $^{3}$ ), cosmic rays, cosmogenic radionuclides (tritium, beryllium, carbon and sodium $^{3}$ ), radioactive rain, radioactive material in the body, radiation product and produced by machines, materials and advanced technology products ${ }^{3}$.

The ionizing radiation in its interaction with matter produces ions directly or indirectly ${ }^{5}$. Therefore, ionizing radiation can be classified as direct or indirect. Ionizing radiation can also be classified as either electromagnetic or particle ${ }^{2}$.

\subsection{Direct Ionizing Radiation}

Direct ionizing radiation corresponds to the rays of electrons (negatrons) and protons or beams of charged particles such as alpha and beta particles, positrons, muons, charged mesons, heavy charged ions and other nuclear particles $^{3,5}$.

These charged particles pass through the biological tissue and they can cause direct ionization on their own ${ }^{5}$. An electron is expelled from the outermost layers or orbits of the atom, creating positive ions, which are more unstable and chemically active than the initial neutral atom ${ }^{5}$. Thus, ionization is the main mechanism of biological alteration induced by ionizing radiation ${ }^{5}$. This type of radiation causes chemical and biological damage by itself. This radiation interacts with a material through the force of Coulomb, by the repulsion or attraction of electrons from molecules and atoms ${ }^{3}$.

For example, it is necessary to have alpha particles with an energy of approximately $7.5 \mathrm{MeV}$ to cause the penetration of the epidermis. The epidermis protects the skin and it is approximately $0.07 \mathrm{~mm}$ thick.

The penetration of alpha particles is small, and the ionization is large. The beta particles have more penetration than alpha particles. Beta particles require an energy of approximately $70 \mathrm{keV}$ to penetrate the epidermis ${ }^{3}$. 


\subsection{Indirect Ionizing Radiation}

Indirect ionizing radiation is made up of gamma radiation, X-rays and neutron rays ${ }^{5}$. These are not charged particles, but they have the ability to expel electrons from the medium, causing ionization ${ }^{5}$. There are not chemical and biological changes by itself with this kind of radiation. This radiation is absorbed by the material and then fast electrons are produced with the energy absorbed. These particles act as direct ionizing radiation, and they can produce the ionization of other atoms of the absorbent material and the rupture of chemical bonds which could produce biological damage ${ }^{2}$.

The process of absorption of X-rays or gamma photons by the material depends of the energy of the photons concerned and the chemical composition of the absorbent material ${ }^{2,3}$. Photons are absorbed through the following processes: Pair production (a high energy photon disintegrates and produces an electron and a positron), The Compton effect (partial absorption of a photon by a free electron) and The Photoelectric effect (total absorption of a photon by an electron bound to the atom $)^{3}$.

$\mathrm{X}$-rays result from the interaction between electrons (when an electron jumps from one orbit of the atom to another). ${ }^{3}$ The X-rays' photons have discrete energies which are equal to the difference of the energy levels (orbits) among the electrons' jump from the respective orbits ${ }^{3}$. Furthermore, X-rays result from the deceleration of electrons through a potential difference as occurs in the X-ray tube. Gamma rays (photons) are produced by a radioactive nucleus when an energy transition occurs from a nuclear state of higher energy to a state of lower energy $^{3}$. Gamma rays have a high penetration and low ionization ${ }^{6}$.

The penetration of radiation into the tissue is expressed by the HVL (Half Value Layer).

For example, the HVL is $3 \mathrm{~cm}$ for X-rays of $100 \mathrm{kV}$ and soft tissue. For Technetium $99 \mathrm{~m}$ gamma rays of $140 \mathrm{keV}$, it is $5 \mathrm{~cm}$. For gamma rays of $1.25 \mathrm{MeV}$ of Cobalt 60 , it is $10 \mathrm{~cm}$.

Neutrons are uncharged particles and they produce indirect ionization. Neutrons interact with the atoms of matter and originate alpha and beta rays, gamma rays or X-rays, which produce ionization ${ }^{5}$. Neutrons are very penetrating, and it is necessary to use water, concrete, paraffin or other materials to stop them ${ }^{5}$.

\subsection{Non-ionizing Radiation}

In the energy range of the electromagnetic spectrum, there are electric and magnetic fields, radiofrequency (RF), microwave, infrared, visible light, and low energy ultraviolet ${ }^{5}$. They are non-ionizing radiation with frequencies in the range from 0 to $300 \mathrm{GHz}$ approximately. This radiation does not have sufficient energy to convert molecules or atoms to ions, but they can produce heat (seemingly reversible) to the molecules ${ }^{5}$. It is due to the rotation, vibration and movement of the molecules ${ }^{5}$. This heating is used for therapeutic and aesthetic effects. The biological effects of this radiation are currently under investigation. It can, however, cause injuries, burns and erythema. Some sources of this type of radiation are:

Electric and magnetic fields sources: People are exposed at home, work, schools, in modes of transport (such as trains), radiators, razors, hair dryers, household appliances and stray currents due to imbalances in the grounding of 
the buildings. This includes, for example, electric and magnetic fields, which are produced where there are electric and magnetic conductors ${ }^{10}$.

Radiofrequency and microwave sources: This applies to induction cookers and welding processes, radio/television systems, mobile telephony and magnetic resonance ${ }^{10}$.

Sources of infrared radiation: Sunlight, tungsten filament lamps, halogen lamps of tungsten filament, light emitting diodes (GaAs diode), xenon arc lamps, melting iron, infrared lamp batteries and infrared lamps in hospitals ${ }^{10}$.

Visible light sources: Sunlight, laser, IPL, welding, projectors and optical devices, general lighting.

Sources of ultraviolet radiation: Sunlight (290-295 nm), industrial arc welding, industrial lamps of ultraviolet radiation, black light lamps, ultraviolet lamps for medical treatment (diagnostic and therapeutic purposes, dermatology), germicidal lamps (250- $265 \mathrm{~nm}$ ), cosmetic tanning (in the UVA region) and general lighting (fluorescent lamps, halogen lamps of tungsten) ${ }^{10}$.

\section{Material and Method}

Burns and injuries can occur due to irradiation (diagnostic equipment and medical treatment: X-rays, radiotherapy, fluoroscopy, laser devices, infrared, radiofrequency) or contamination (for example, those produced by nuclear accidents, wars).

Ionizing Radiation.- The first injuries and burns caused by ionizing radiation were due to skin reactions in the use of radiology equipment after the X-ray's discovery by Roentgen. At the beginning of the last century, skin cancers and leukemia appeared in the first people who worked with radiation: miners of live rock gallery, neoplasms in painters of radio spheres, atomic bomb survivors, radiotherapy patients and animals undergoing radiation in laboratory experiments ${ }^{3}$.

After the nuclear tests in Nevada (1950), children from southwest Utah and Nevada who were exposed to radioactive rain showed an increase in the frequency of thyroid cancer $^{3}$. In addition, a test of thermonuclear weapons in Bikini Atoll, in 1954, produced also a frequency increase of thyroid cancer in the inhabitants of the Marshall Islands. The increase was proportional to the received dose in the thyroid gland in childhood due to the high levels of radioactive fallout ${ }^{3}$.

From 1945 to 1987, there were over 285 accidents in nuclear reactors in different countries with 1350 affected and 33 fatalities. More accidents have occurred in installations with sources for radiotherapy ${ }^{6}$. Important information has also been obtained from nuclear plant accidents such as the Chernobyl (1986) and the Three Mile Island nuclear reactor (1979) $)^{4}$.

In the Chernobyl accident, radioactive material was released, and radiological diseases and burns occurred in more than 200 people $^{1}$. The long-term effects are not predictable, but estimates assume that around 30,000 additional deaths from cancer can occur during the next 70 years due to the accident ${ }^{3}$. In addition, children of Belarus and 
Ukraine who were contaminated by radionuclides released in the Chernobyl accident showed an increased incidence of thyroid cancer ${ }^{3}$.

The production of the atomic bomb has had dramatic consequences in the history of humanity. Important scientific information has been obtained from the events that occurred in Japan in August 1945, from the Japanese survivors of Hiroshima and Nagasaki ${ }^{4}$. Many of the deaths were due to explosions and burns, but in the following approximate thirty years, 500 cases of radiation inducing cancer and leukemia were reported.

\subsection{Cases}

1.- Nuclear accident in 1958 at the Laboratory of Los Alamos, New Mexico, United States.- The emission caused a fatal radiological injury to an employee. The average body exposure was around $49 \mathrm{~Gy}^{3}$. The symptoms included: physical collapse, semi-consciousness, abdominal pain, anoxia, hypotension, circulatory failure, irritability and antagonism. Clinical-pathological alterations were observed in the urinary and hematopoietic systems $^{3}$. Leukocyte count changes were the indicator of the severe irradiation ${ }^{3}$.

2.- Windscale reactor accident in the United States in 1957.- The reactor was a producer of plutonium with uranium fuel. Bequerel, cesium, strontium and iodine were released into the environment ${ }^{3}$. The maximum absorbed dose outside the installation was about $35 \mu \mathrm{Gy} / \mathrm{h}$. It was forbidden to consume milk in areas near the installation. In addition, fourteen workers received doses between $30 \mathrm{mSv}$ and $46 \mathrm{mSv}$ per quarter during reactor control $^{3}$.

3.- Gulf Oil accelerator accident in the United States in 1967.- The accelerator used was a Van de Graaf model. Three people were seriously exposed: the first received about $1 \mathrm{~Gy}$ in the whole body, the second about 3 Gy in the whole body, and the third approximately $6 \mathrm{~Gy}$ in the whole body, $30 \mathrm{~Gy}$ in the feet and $60 \mathrm{~Gy}$ in the hands. The symptoms were: nausea, vomiting and muscle aches ${ }^{3}$.

4.- Accident of the SL-1 reactor prototype, in Idaho, United States in 1961.- This reactor was used for the production of electrical energy. Three victims were registered, as a result of the high activity fission ${ }^{3}$.

5.- Industrial and analytical $X$-ray machines.- Occasionally, the absorbed dose rates are $5 \mathrm{~Gy} / \mathrm{s}$. Between the years of 1950 and 1970, most of the radiological accidents were due to industrial radiography. Commonly used $\mathrm{X}$-ray systems offer reasonable security ${ }^{3}$.

6.- Accident of Three Mile Island, United States, in 1979.- The physical and sanitary personnel of Three Mile Island had enough experience, but the consequences resulting from the accident were so many that it was not possible to solve all issues ${ }^{3}$. This accident caused the release of $7.4 \mathrm{TBq}$ of Iodine 131 and levels of strontium 90 and Cesium $137^{3}$.

7.- Radiological accident of Goiania in Brazil, in 1985.- The ${ }^{137}$ Cs teletherapy unit was stolen in a clinic in Goiania. The fountain capsule was broken during disassembly and in one part of the city, Cesium 137 chloride powder was diffused. The parts of the fountain assembly and the dust of Cs 137 - which glowed in the dark with bluish color - were sold to several families, who developed gastrointestinal symptoms ${ }^{3}$. In addition, the patients 
developed skin lesions. Approximately 249 people suffered contamination with many requiring hospitalization. The absorbed dose was between 4 and $7 \mathrm{~Gy}^{3}$.

8.- Accident of the Chernobyl Nuclear Power Plant in Ukraine (1986).- $1900 \mathrm{PBq}$ of fission and fuel products were released for 10 days. The radioactive isotopes released were Iodine 131, Strontium 90, and Cesium 137. The main risks consisted of ingestion of contaminated food and external irradiation due to surface deposition ${ }^{3}$. This accident doubled the total number of deaths worldwide caused by radiological accidents $(61)^{3}$.

9.- A 50 year old patient had a burn and necrotic lesion and symptoms of pain in the back.- It occurred in 2002, after five hours exposed to radiological procedures during the placement of a stent, due to an angioplasty ${ }^{11}$. There was an increase in the echogenicity of subcutaneous cell tissue ${ }^{11}$.

10.- A 52 year old patient, during the placement of a stent, was exposed for six hours to $X$-rays.- The patient suffered from blisters with a Herpes Zoster. Following this,, the patient was diagnosed with radiodermatitis. Additionally, the patient presented flap necrosis, tissue dehiscence, lumbar back exposure and necrotic remains ${ }^{11}$. 11.- A 78 year old patient, during the placement of three stents.- The patient underwent a prolonged exposure to $\mathrm{X}$-rays. The patient manifested an ulcer in the right scapular infra area ${ }^{11}$.

12.- A 76 year old patient during a stent placement.- The patient underwent a prolonged X-ray procedure. The patient presented burns and necrotic lesions ${ }^{11}$.

13.- A patient of 52 years, during angioplasty of three stents.- The patient was exposed to hours of fluoroscopy. The patient suffered an increase in the echogenicity of the exposed area and a loss of dermohypodermic differentiation ${ }^{11}$.

14.- Thirty patients with skin burns due to ionizing irradiation at the General Hospital of Mexico.- The ages of the patients were between 14 and 78 years old. The time of appearance of the lesions was between 24 hours to 12 years. In 20 of them, the treatment was justified and the cause of the treatment was malignant neoplasms of the breast and internal genital organs. A 47 year old patient was repeatedly subjected to fluoroscopic analysis for a duodenal ulcer. The patient returned after twelve years with discomfort, and an area of radiodermatitis in the dorsolumbar region was verified ${ }^{9}$.

In three patients, a radiodermatitis with radionecrosis was developed in the hemangioma of the face, fifteen years later. In five patients, the application was unjustified, such as the case of an elbow burn due to the application of ionizing irradiation for the treatment of joint pain ${ }^{9}$. Two patients were subject to an accidental irradiation. One of them was by a doctor who exposed his hands to the fluoroscopic screen to remove a foreign body from the hand of another patient. The other case was due to a patient who introduced a radioactive capsule into his clothing, with severe symptoms and a deep burn in the gluteal region ${ }^{9}$.

The treatment consisted of replacing irradiated tissues with healthy tissues ${ }^{9}$.

Non-ionizing Radiation.-Among the types of non-ionizing radiation risks, there are: electromagnetic fields, radiofrequency, microwave, infrared, visible light (laser, IPL) and low energy ultraviolet ${ }^{6}$. 
(a) Electromagnetic Fields

Electromagnetic fields can induce leukemia and neurological and behavioral reactions: bradycardia, headaches, dizziness, memory failures, depression ${ }^{6}$. In addition, the electric current (especially direct current, due to the electrolysis effect) can cause burns. With a current greater than $4 \mathrm{~A}$, deep burns occur in the tissue. In addition, the galvanic apparatus used for aesthetic iontophoresis can produce chemical burns from sodium hydroxide under the cathode. Thermal burns are caused by excess heat in areas of high skin resistance. In a hospital, there are many pieces of equipment and devices carrying current and these require the user to take the appropriate safety measures to avoid injuries and burns.

\section{(b) Radio Frequency Fields, Microwave}

This is composed of radio, television, telephony, mobile, radar, radio communication, microwave ${ }^{6}$. The radiofrequency or microwave fields heat in deep areas ${ }^{6}$. The biological effects due to deep heating are under investigation. In the two world wars, there were effects from military radars on the operator. Conditions, such as headaches, eye pain, irritation, emotional instability, tiredness and impaired intellectual ability were observed. In addition, when the Soviets subjected US embassy personnel to radiation, in order to intercept their communications, it was discovered that most of the people assigned to this embassy subsequently developed cancer. Alongside these, the radiofrequency apparatus used for cosmetology can cause erythema, reddening of the skin and small irritations. There is no evidence of cancer induction by microwave radiation due to mobile telephony, and the biological effects are being investigated. Radiation due to the cell phone is more dangerous with phones which have a high SAR (greater than $2 \mathrm{~W} / \mathrm{kg}$ ) and also those which work with a very high frequency (greater than $2500 \mathrm{MHz})^{5}$. However, the use of a cell phone in the presence of a high voltage line can induce an electric arc which could cause a burn. This is because the high voltage can produce an electric arc under certain ambient humidity conditions ${ }^{5}$. The electric arc is a kind of continuous electric discharge. It produces intense heat and light. The microwave radiation of the cell phone increases the possibility of an electric arc. It is because the electromagnetic radiation increases the electric field strength reaching the electric field value needed to produce it at that distance from the respective high voltage line. Therefore, for example, a person on a balcony near a high-voltage line and with a cell phone can suffer the consequences of an electric arc and lethal burns ${ }^{5}$.

\section{(c) Infrared Radiation}

Infrared radiation has thermal effects and it is present in sunlight and lamps. In the tissue, it produces warming of the skin, burns and eye lesions ${ }^{6}$. There are three types: IRA, IRB, IRC. IRA can cause retinal involvement and lens opacities due to iris heating. IRB can cause temporary damage to the cornea and aqueous humor. IRC can cause pain and corneal burns ${ }^{6}$.

\section{(d) Visible Light (Laser)}

Visible light is present in sunlight, welding equipment and some devices and devices such as laser, IPL (used in cosmetology). This type of radiation has photochemical and thermal effects. An example of the application of light 
is the laser which can be a risk to the eyes and skin. The operation of lasers is at discrete wavelengths, although there are lasers such as the argon laser or the IPL which emits several different lines in the ultraviolet region ${ }^{10}$.

An exposure to the retina can cause damage to the cornea and lens (type 2 and 3 laser) ${ }^{10}$. Some lasers (laser type 4 ) such as surgical lasers and materials processing lasers used for welding can be a risk to the skin and cause cuts or burns ${ }^{10}$. For the safe use of lasers, it is recommended to confine the radiant energy of the laser and take control measures and instructions to personnel and the use of protective glasses ${ }^{10}$. In addition, slight burns, blisters and hyper / hypopigmentation changes in skin texture may occur due to the use of laser or IPL devices in cosmetology.

\section{(e) Ultraviolet Radiation}

It is present in sunlight. Also, it is emitted by many devices in industry, science and medicine ${ }^{6}$. This type of radiation has photochemical effects. In the eye, it can lead to cataracts and photoconjunctivitis ${ }^{6}$. The effects on the skin are erythema or sunburn, photosensitization, and delayed effects such as skin aging and carcinogenesis ${ }^{6}$.

\section{Results}

Ionizing Radiation.-The rays with a lower frequency (lower energy) and longer wavelength are less penetrating and remain on the surface (alpha, beta, and ultraviolet rays). The rays with a higher frequency (higher energy) and shorter wavelength produce rays which penetrate deep (high energy X-rays and gamma rays). In both cases, there is the formation of intracellular free ions or free radicals, which cause destruction of the cells, whether superficial or deep ${ }^{9}$. For charged particles, the biological damage will be greater as the larger the charged particle and the lower its energy. The penetration capacity will be larger as the larger its energy and the smaller the size ${ }^{5,6}$. The energy released by each ionization is around $33 \mathrm{eV}$ (air ionization). It is sufficient to cause the rupture of a strong chemical bond ${ }^{2}$. Thus ${ }^{2}$, the associated energy of a $\mathrm{C} \stackrel{\mathrm{m}}{=} \mathrm{C}$ carbon bond is approximately $4.9 \mathrm{eV}$.

When X-ray photons or gammas and uncharged or charged particles are absorbed into materials (biological), it could interact with cell targets (DNA for example) ${ }^{2}$. The atoms can be excited or ionized and it could produce biological damage ${ }^{2}$. It is the direct action of radiation. The ionizing radiation can also interact with other molecules or atoms in the cell (water for example), producing fast electrons, which produce free radicals. These can, in turn, break bonds and cause critical damage to cell targets ${ }^{2}$. This is the indirect action of radiation (not to be confused with the direct and indirect ionizing radiation).

The biological effects of this type of radiation can be observed in: the DNA (a dose of 2 Gy is enough to produce many lesions and sometimes reversible (effects of proton or alpha particle (concentrated radiation) are less repairable than those produced by X-rays or gamma rays (dispersed radiation), the genes (mutations directly proportional to the dose, a single ionizing particle which crosses the DNA is sufficient to cause a mutation), the chromosomes (chromosomal aberrations in lymphocytes are the biological dosimeter), the cell survival (inhibition of mitosis, 1-2 Gy is enough to decrease the surviving population around 50\%), the tissues (division cells are more sensitive, if the volume of irradiated tissue is small enough, or if the dose accumulates slowly enough, then the severity of the lesion can be decreased by the compensatory proliferation of the surviving cells) ${ }^{6}$. The effects of the radiation vary according to the dose-response relationships, clinical manifestations, chronology 
and prognosis. The effects of the radiation can be hereditary (in the descendants) or somatic (in the irradiated subjects). The somatic can be acute or late. The acute effects are due to the decrease of progenitor cells in the affected tissues and they can be induced by doses large enough to kill many of these cells. These effects are considered deterministic (not stochastic).

The effects can also be stochastic and non-stochastic (deterministic). Stochastic effects appear at random, have no relation to the dose and result from the random molecular alterations in individual cells. Stochastic effects have an annual dose limit of $50 \mathrm{mSv}$. The deterministic effects (carcinogenic and genotoxic) ${ }^{6}$ increase as a linear dose function and have a dose limit of $500 \mathrm{mSv}$ for any organ, except for the lens with $150 \mathrm{mSv}$.

Table 4. Dose limit ${ }^{11}$

\begin{tabular}{|c|c|c|}
\hline & Dose limit (European Commission) & \\
\hline & Workers (Radiation) & Members of the public \\
\hline Whole Body & $20 \mathrm{mSv} / \mathrm{year}$ & $1 \mathrm{mSv} / \mathrm{year}$ \\
\hline Hands, Skin & $500 \mathrm{mSv} / \mathrm{year}$ & $50 \mathrm{mSv} / \mathrm{year}$ \\
\hline Eyes & $150 \mathrm{mSv} / \mathrm{year}$ & $15 \mathrm{mSv} / \mathrm{year}$ \\
\hline
\end{tabular}

The exposure to this radiation below the permitted values will not result in a deterministic effect. Shields are used to limit the dose which enters the tissue and thus the attenuation is the maximum possible. For photons, materials of high atomic number (lead) are used. For beta particles, low atomic number materials are used. For neutrons, concrete or thinner shields with up to three different layers are used.

Table 5. Shielding for different types of radiation

\begin{tabular}{|c|l|}
\hline & Shields \\
\hline Electrons & Low Z (atomic number) materials: aluminum or concrete \\
\hline Ions & High Z (atomic number) materials: tantalum or platinum \\
\hline X-rays and gamma rays & Ordinary concrete, roller door steel, shield lead \\
\hline Neutrons & Ordinary concrete \\
\hline
\end{tabular}

The acute effects are: acute radioepidermatitis (greater than 10 Gray for a few minutes, it appears maximum in 2 months), alopecia (greater than 3 Gray for a few minutes, it appears in 2 months), oligospermia ( 0.3 Gray for a few minutes, it appears in 2 months $^{6}$ ). The erythema occurs due to the vasodilation of the capillaries of the dermis and can occur with a single dose from 3 to $10 \mathrm{~Gy}$. The erythema may appear between the first and the second day of irradiation. This erythema is usually cured. If the erythema is large, hyperpigmentation occurs. It is mainly due to an increase of the melanin synthesis ${ }^{8}$. The degree of pigmentation varies from one region to another in the same 
individual and from one person to another. Moderate lesions can be cured with or without few sequelae. The reepithelization takes place after 6-8 weeks with thin skin, and then it looks normal after 2-3 months ${ }^{8}$.

If the dose exceeds $10 \mathrm{~Gy}$, an erythema with peeling will occur. It is known as dry radiodermatitis which is caused by the increased division of dead cells. With higher doses, a large number of basal cells are destroyed, and the cells of more superficial strata are shed and fall. Then, the dermis is exposed. This is known as wet radiodermatitis ${ }^{8}$. If the dose is greater than $25 \mathrm{~Gy}$, acute radionecrosis can occur with large vascular and connective tissue lesions. It evolves as an ulcer for a few months ${ }^{8}$. Hair follicles and growth organs are radiosensitive. The sweat and sebaceous glands are relatively radioresistant. Moderate doses produce minor changes, which are expressed as dry skin. At high doses, atrophy and complete destruction of the glands occurs.

The effects described above are the early effects of ionizing radiation on the skin. Late effects on the skin include the appearance of atrophic skin and depigmentations, with ulcerations and deep fibrosis. The epidermis is dry. It is due to the decrease in the secretory activity of the sebaceous and sweat glands. In addition, subendothelial hyperplasia in the blood vessels results in the presence of telangiectasias ${ }^{8}$. Atrophic skin shows a thinned, flaky epidermis. It is very sensitive to lesions due to minimal trauma, which can lead to necrosis ${ }^{8}$.

With multiple repeated exposures for a long time at a low dose of radiation, it can lead to chronic radiodermatitis, in which the skin can become hypertrophic or atrophic. The chronic radiodermatitis is produced with a cumulative dose of 10 Gy in 6 months of exposure. The term of appearance is 5 years $^{6}$.

The hypertrophic skin presents hyperkeratosis. It is more brittle and fragile than normal, with exaggerated folds and total or partial hair removal. Chronic radiodermatitis is related to the incidence of skin cancers (spinocellular epitheliomas) ${ }^{8}$. Sometimes skin ulceration occurs, which is very difficult to cure, due to the poor vascularization and the existence of damaged connective tissue.

Non-ionizing Radiation.-This radiation does not have sufficient energy to ionize matter. This type of radiation acts by heating and induction of currents in the body ${ }^{6}$. The biological effect of non-ionizing radiation is under investigation (if they can cause mutations and cancer) ${ }^{3}$.

The electric and magnetic fields can induce leukemia and neurological and behavioral reactions ${ }^{6}$. The radiofrequency or microwave fields heat in deep areas and their biological effects are under investigation ${ }^{6}$. Radiofrequency can also cause burns, erythema, redness of the skin, small irritations: for example, in its application in cosmetology. In respect to microwave radiation, such as the use of the mobile telephone, the public limit is an energy per unit of mass not exceeding $2 \mathrm{~W} / \mathrm{kg}$ (SAR) for frequency from $450 \mathrm{MHz}$ to $2500 \mathrm{MHz}$ and at a distance of $2 \mathrm{~cm}$ from the mobile. Almost all cell phones are below these limits (between 800 and $2200 \mathrm{MHz}$ and between 0.3 and $1.5 \mathrm{~W} / \mathrm{kg}$ ). For example, the penetration of waves with frequency of $900 \mathrm{MHz}$ is approximately $3 \mathrm{~cm}$ inside the brain. An energy of $4 \mathrm{~W} / \mathrm{kg}$ or a temperature rise of $1{ }^{\circ} \mathrm{C}$ is required to cause biological damage. The investigations of the excessive use of mobile phones are not yet conclusive concerning the effects as to the modification of the DNA of the cells, the loss of memory and the possible appearance of tumors in the brain. The primary concern is that the cancer appears after many years and also depends on the type of life the person leads 
and hereditary factors. At present, it is accepted that the continuous application of microwaves in the brain can produce remarkable changes in the human organism after a considerable time interval ${ }^{5}$. In addition, the use of a cell phone in the presence of a high voltage line can induce an electric arc which could cause a burn.

Infrared radiation can produce corneal pain and burns in the eye and in the tissue can produce warming of the skin, erythema and burns ${ }^{6}$.

One of the applications of the visible light is the laser which can be a risk to the eyes and skin. Exposure to the retina can cause damage to the cornea and lens (laser type 2 and 3$)^{10}$. Some lasers (laser type 4) such as surgical lasers and materials processing lasers used for welding can be a risk to the skin and cause cuts or burns ${ }^{10}$. Furthermore, slight burns, blisters and hyper/hypopigmentation changes in the skin texture may occur due to the use of laser or IPL devices in cosmetology.

The ultraviolet light can produce cataracts, photoconjunctivitis in the eye ${ }^{6}$ and the effects on the skin are erythema or sunburn, photosensitization and delayed effects such as skin aging and carcinogenesis ${ }^{6}$.

\section{Discussions and Conclusions}

Ionizing Radiation.- Due to the more frequent and beneficial use of ionizing radiation in medicine, industry and science (nuclear power plants, radiographs, nuclear medicine, radiopharmaceuticals, radiotherapy) and for military and peaceful applications, the effects of the ionizing radiation have been investigated and discussed thoroughly. It has allowed the development of measures to protect human health against ionizing radiation. Studies of the biological effects of ionizing radiation continue as new devices and technologies using this type of radiation are developed. Ionizing radiation can induce cancer and the probability of onset grows with the dose of radiation received.

The increase in the use of ionizing radiation in industry, modern medicine and different types of scientific laboratories has led to an increase in skin lesions and burns, either intentionally (radiotherapy), pollution (nuclear accidents, wars) or accidentally (work) ${ }^{9}$. The exposure to ionizing radiation below the threshold will not result in deterministic effects ${ }^{6}$. In addition, the protection standards for exposed workers must be based on the risk independent of the level of exposure.

Safety precautions have removed the acute injuries of exposed workers and patients treated with radiotherapy. In the use of radiotherapy, the therapeutic dose must be precise so as not to cause burns ${ }^{9}$. However, currently many patients on radiation treatments have some lesion and burn of normal tissue.

The biological effects of the ionizing radiation result mainly of the damage to $\mathrm{DNA}^{2}$. The ionizing radiation can eject electrons from the atom or molecule and transform the atom or molecule into an ion. In the case of tissues, it can cause damage to DNA, causing damage and mutations in its genetic code and cancer ${ }^{2,3}$. When a portion of the organism is irradiated, high doses are required to produce considerable lesions. Each type of tissue will have a different response depending of its radiosensitivity. The carcinogenic and genotoxic effects increase proportional 
to the dose (linear function and without threshold). The sensitivity of the exposed cells varies according to the proliferation rate. The embryon and the child are the most vulnerable.

The skin is the first barrier that radiation finds in the body, although there may also be cases of inhalation or ingestion of radioactive substances ${ }^{8}$. The cells of the basal layer of the skin are the most radiosensitive and they are reached by very low energy radiations, even from the range of ultraviolet radiation ${ }^{8}$. Consequently, skin lesions are the most frequent of all radioinduced histopathological reactions. Mature cells which are not in the process of division are radioresistant, but cells which divide within a tissue are radiosensitive.

The effects of radiation are on: the DNA (with a dose of $2 \mathrm{~Gy}$, many DNA lesions can occur), genes (poorly repaired or unrepaired DNA can cause mutations, it increases as a linear dose function), the chromosomes (radiation lesions in the genetic apparatus can produce aberrations in the number and structure of chromosomes), the cell survival

(inhibition in the cell division, affecting in greater quantity the dividing cells, with 1-2 Gy, the population is reduced by 50\%), the tissues (division cells are more sensitive, the severity of the lesion can be decreased by the compensatory proliferation of surviving cells if the dose accumulates slowly enough the volume or if the irradiated tissue is small enough) ${ }^{3}$.

The clinical manifestations of the lesions are on: the skin, the bone marrow and the lymphoid tissue, the intestine, the gonads, the respiratory system, the lens of the eye, and other tissues ${ }^{3}$.

The germ layer cells of the epidermis are radiation sensitive. The exposure of the skin to a dose of approximately $6 \mathrm{~Sv}$ or greater results in a redness, erythema or burns of the exposed area. It appears on the first day and continues for two to four weeks with a deeper erythema and with hair removal. If the dose is greater than 10 to $20 \mathrm{~Sv}$ approximately, necrosis, ulceration and blisters may occur within two to around four weeks. It results in atrophy and ulceration months or years later ${ }^{3}$.

In summary, the exposure to the ionizing radiation can lead to injuries with fatal results to inherited disorders, birth defects and cancers which appear within decades, years or months. The extent of the injury and the effects such as skin burns depend on the type of radiation as well as the exposure conditions and doses ${ }^{3}$. These effects are found in greater amounts in radiotherapy patients or people with severe irradiation or nuclear accidents or atomic bombs.

Non-ionizing Radiation.-The interest in the biological effects and health consequences of the non-ionizing radiation has increased. The biological effect of non-ionizing radiation is under investigation and it is not proven that this kind of radiation can induce cancer, mutations. Non-ionizing radiation can cause injuries, electrocution, eye injuries (cataracts) and skin lesions (erythema, burns). Non-ionizing radiation does not produce ionization of the molecules ${ }^{3}$. The only phenomena observed during the absorption of the energy of non-ionizing radiation are the excitations or increase of the rotation and vibration energy of the molecules which results in the heating of the molecules. Non-ionizing radiation is transmitted by transmission lines, power stations, radio and television antennas, computers, radars, mobile phones, microwaves, radio frequency devices, lasers and other electronic, medical and optical equipment ${ }^{5}$. For example, mobile phones emit microwave radiation which can interact with the 
environment ${ }^{5}$. The amount of radiation which enters into the body depends on the proximity and orientation of the source, the genetic characteristics of the person and the frequency (energy) and density of the source. The eyes, brain and sexual organs are the most sensitive to the effects of continuous exposure such as radio and microwave frequencies.

Burns due to the cell phone use can occur with phones which have a defective battery or phones with replacement batteries. The precautions to be taken to avoid burns with cell phones are: turning off your cell phone when you are near a service station, avoiding the use of unsupported cell phone accessories and avoiding use of the phone near a high voltage line to avoid an electric arc. For safety, cell phones should be kept away from radiation sensitive parts of the human body. It is also recommended not to place the cell phone near other electrical appliances.

In addition, research has been conducted about the effects of low intensity magnetic and electric fields and their relationship with cancer, reproduction, neurological and behavioral reactions ${ }^{10}$. The main mechanism for interaction of radio frequencies and microwaves is through heating, while high intensity fields can induce currents in the body ${ }^{10}$. The radiofrequency can cause burns, erythema, redness of the skin, small irritations. Infrared radiation can produce warming of the skin, erythema and burns in the tissue and corneal pain and burns in the eyes $^{6}$. Visible light and its application: the laser, can constitute a risk for the eyes and the skin: damages in the cornea and the lens, cuts or burns ${ }^{10}$. Additionally, slight burns, blisters and hyper / hypopigmentation changes in the skin texture can occur. Ultraviolet light can produce erythema or sunburn, photosensitization, and delayed effects on the skin such as skin aging and carcinogenesis and effects on the eye such as cataracts and photoconjunctivitis $^{6}$. A table of radiation types with their respective effects is showed in the table 6 .

Table 6. Radiation with its effects

\begin{tabular}{|c|c|c|c|}
\hline Radiation & Type & Units & Effects \\
\hline $\begin{array}{c}\text { Gamma rays, X-rays, } \\
\text { High energy Ultraviolet }\end{array}$ & Ionizing & Joule, $\mathrm{KeV}, \mathrm{MeV}$ & $\begin{array}{c}\text { Ionization, rupture of chemical and molecular } \\
\text { bonds, DNA damage, genotoxic effects }\end{array}$ \\
\hline $\begin{array}{c}\text { Low energy Ultraviolet, } \\
\text { Visible light, Infrared }\end{array}$ & Non-Ionizing & $\mathrm{nm}, \mu \mathrm{m}, \mathrm{cm}$ & $\begin{array}{c}\text { Electronic excitation, rotation and vibration } \\
\text { of molecules, biochemical and heating effects }\end{array}$ \\
\hline $\begin{array}{c}\text { Madicrowave, } \\
\text { Radrequency }\end{array}$ & Non-Ionizing & Hertz, $\mathrm{Hz}$ & $\begin{array}{c}\text { Intense induced currents, vibration and } \\
\text { rotation of molecules, heating }\end{array}$ \\
\hline $\begin{array}{c}\text { Magnetic and Electric } \\
\text { Network }\end{array}$ & Non-Ionizing & Hertz, Hz & $\begin{array}{c}\text { Small induced currents, various cellular } \\
\text { effects, neurological and behavioral reactions }\end{array}$ \\
\hline
\end{tabular}

Below, It is included the electromagnetic spectrum with different radiation generating devices ${ }^{4}$ :

$1 \mathrm{~Hz}-300 \mathrm{kHz}$ : LF, ELF (low and very low frequency radiation): Device electric fields, electrical network, AM frequency radio sections, video monitors $\left(3-3 \times 10^{4} \mathrm{~Hz}\right)$. 
300 KHz-300 MHz: RF (radiofrequency): AM radio sections, FM radio, Medical shortwave (27 MHz), NMR: magnetic resonance (2.13 MHz for magnetic field of $1 \mathrm{~T}$ (Tesla)).

300 MHz-300 GHz: M.O. (microwave): Household appliances use of microwave, mobile telephony (900 MHz, $1800 \mathrm{MHz}$ ), radar, microwave for medical physiotherapy: $2450 \mathrm{MHz}$ and $915 \mathrm{MHz}$.

$300 \mathrm{GHz}(\mathbf{1 ~ m m})-\mathbf{7 8 0} \mathbf{~ n m}$ : IR (infrared): Sunlight, laser, heat therapy equipment. $780 \mathbf{n m}-\mathbf{4 0 0} \mathbf{~ n m}$ (Visible light): Sunlight, laser, phototherapy.

$400 \mathrm{~nm}-100 \mathrm{~nm}$ : UV (ultraviolet): Sunlight, materials above $2700 \mathrm{~K}$, radiotherapy treatments, food and air sterilization, fluorescent tubes.

1 eV-200 keV: X-rays: X-rays tubes, synchrotron, accelerator.

$200 \mathrm{keV}$ (or less) -......: Gamma Rays: Radioactive isotopes, nuclear reactors, cosmic rays, (explosions of supernovae or nuclei of active galaxies, they do not reach the earth's surface, as the high atmosphere absorbs them).

It is customary to express the non-ionizing radiation of lower energy by its frequency $(\mathrm{Hz})$ (radiofrequencies and microwaves), the infrared (IR) regions, visible light and ultraviolet (UV) by its wavelength (nm), and the Rem ionizing (X-rays and gamma rays) for its energy ( $\mathrm{keV}$ or $\mathrm{MeV})$.

\section{References}

[1] Lesiones por radiación, Dra. Quintana, Dr. Iglesias, Hospital General Universitario Gregorio Marañon.

[2] Radiobiology for the Radiologist, Eric J. Hall, Fourth edition, Lippincott Company, Philadelfia, 1994.

[3] Radiaciones Ionizantes, Robert N. Cherry, Jr., Enciclopedia de Salud y Seguridad en el Trabajo.

[4] Nuclear Medicine Science and Safety, A source of reference concerning the nature and safety of nuclear medicine procedures, intended for medical, paramedical nursing and technical staff in nuclear medicine deparments, Dr. A. C. Perkings, John Libbey \& Company Ltd, 1995.

[5] Giovanni Alcocer, Priscilla Alcocer, Xavier Alcocer, Carlos Marquez, Burn due to the use of the mobile telephone and interaction of the non-ionizing radiation with the electric field of high voltage, Mediterranean Journal of Basic and Applied Sciences (MJBAS), Volume 2, Issue 2, Pages 48-58, April-June 2018.

[6] Riesgos Físicos, Enfermedades profesionales.

[7] Principios de urgencias, emergencias y cuidados críticos, UNINet.

[8] Radiobiología General, F. Sendra Portero y M. Martínez Morillo.

[9] Lesiones cutáneas producidas por radiación ionizante, César Henriquez Izaguirre.

[10] Radiaciones no ionizantes, Bengt Knave, Enciclopedia de Salud y Seguridad en el Trabajo.

[11] Diagnóstico y Tratamiento de las lesiones producidas por exposición a radiaciones ionizantes, Dra. Mercedes Portas, Jefe de Departamento, Hospital de Quemados. 
[12] ¿Qué es la radiación?, ¿Cómo nos afecta la radiación?, ¿De dónde procede la radiación?, Ministerio de Salud, Gobierno de El Salvador, Unámonos para crecer.

[13] The Physics of Radiation Therapy, Faiz M. Khan, Ph. D., Second Edition, William \& Wilkins Editor, 1994.

[14] Física y Biofísica: Radiaciones, J. Dutreix, A. Desgrez, B. Bok, C. Chevalier, primera edición, A.C. Madrid Editorial, 1980.

[15] A Theoretical Approach for Experiments in Modern Physics, Giovanni Alcocer, Lambert Academic Publishing, 2015.

[16] Hübscher. J. Klaue, W. Pflüger - S. Appelt, Electrotecnia curso elemental. Deutsche Gesellschaft für Technische Zusammenarbeit GmbH, Editorial Reverté S.A, (1987); 42:1410 p. 125-140, 221-232.

[17] Stanislav Misák, Mathematical model of electric arc respecting MAYR Theory in EMTP-ATP. Acta Electrotechnica e Informatica; 2008; 8:3 66-69. 